\title{
Migration behavior and aggregation mechanism of SiC particles in silicon melt during directional solidification process
}

\author{
Yue Yang1', **Shi-qiang Ren ${ }^{1,2}$, Da-chuan Jiang', Zhi-qiang Hu', Yi Tan', *Peng-ting Li ${ }^{1,3}$ \\ 1. School of Materials Science and Engineering, Dalian University of Technology, Dalian 116024, China \\ 2. School of Medicine, Liaocheng University, Liaocheng 252000, Shandong, China \\ 3. State Key Laboratory of Advanced Special Steel, Shanghai University, Shanghai 200444, China
}

\begin{abstract}
SiC inclusions in a multicrystalline silicon ingot have a negative effect on the performance of solar cells. The migration behavior and aggregation mechanism of $\mathrm{SiC}$ particles in the silicon melt during the directional solidification process was studied. Results show that $\mathrm{SiC}$ particles collide and aggregate in the melt due to the effect of melt flow. Larger aggregation of SiC particles is easily deposited at the bottom of the melt, whereas smaller $\mathrm{SiC}$ particles are pushed to the top of melt. Meanwhile, the particles migrate to the edge of melt under the effect of electromagnetic force. Furthermore, the enrichment region of $\mathrm{SiC}$ particles can be controlled by adjusting the temperature field distribution of the melt. With an increase of the melt temperature, the SiC particles are enriched at the top of the silicon ingot, indicating that $\mathrm{SiC}$ particles can be effectively separated from silicon.
\end{abstract}

Key words: polycrystalline silicon; SiC; directional solidification; migration
CLC numbers: TG146
Document code: $\mathrm{A}$
Article ID: 1672-6421(2021)06-550-07

\section{Introduction}

With the rapid development of the photovoltaic industry, large-sized crystalline silicon produced by directional solidification attract more and more attention for its lower production cost ${ }^{[1,2]}$. However, the introduction of impurities such as carbon cannot be avoided due to the volatilization of graphite parts during the production process. These impurities will concentrate on the top of the silicon ingot due to the segregation effect, resulting in the waste of a large amount of silicon ingots ${ }^{[3-5]}$. Meanwhile, the recycling of silicon scrap is greatly limited due to its higher content of $\mathrm{SiC}$ inclusion, which can cause defects on the surface of the wafer and reduce the performance of solar cells ${ }^{[6-9]}$. Therefore, the effective removal of $\mathrm{SiC}$ inclusion has great significance for the recycling of the silicon scrap.

Considerable efforts have been made to separate $\mathrm{SiC}$

\section{*Peng-ting Li}

Male, Ph.D., Associate Professor. He is engaged in the research on microstructure modification and solidification control of Al-Si alloys and superalloys.

E-mail: ptli@dlut.edu.cn

**Shi-qiang Ren

E-mail: rsqyx@foxmail.com

Received: 2021-05-30; Accepted: 2021-08-03 inclusions from silicon ${ }^{[10-13]}$. Centrifugal stirring, as a pretreatment method, can separate $\mathrm{SiC}$ particles from the wafer cutting slurry, but it is limited in industrial applications due to its inefficiency ${ }^{[14]}$. Zhang et al. ${ }^{[15]}$ tried to separate $\mathrm{SiC}$ particles from molten silicon by filtering, but the removal effect for fine particles is not ideal. Electromagnetic separation and directional solidification, as an effective and clean method, has been used to purify polysilicon ${ }^{[16-21]}$. It has been found that the $\mathrm{SiC}$ inclusions tend to enrich at the edge of the melt due to the effect of electromagnetic force. However, the influence of electromagnetic field on the aggregation mechanism of $\mathrm{SiC}$ particles has not been discussed in detail. Liu et al. ${ }^{[22]}$ revealed the distribution of $\mathrm{SiC}$ inclusions in a polycrystalline silicon ingot during the directional solidification process, but the effective removal of $\mathrm{SiC}$ has not been achieved. In general, the distribution of $\mathrm{SiC}$ in the silicon ingot has been widely studied, but the migration behavior and aggregation mechanism of $\mathrm{SiC}$ particles have not been revealed systematically, which limits the removal efficiency of SiC inclusions.

In this study, the distribution of inclusion particles in a silicon ingot under the combined action of electromagnetic field and directional solidification was investigated. Meanwhile, combined with the numerical simulation by COMSOL Multiphysics, the effect of the 
temperature field on the migration behavior of $\mathrm{SiC}$ particles was studied. Furthermore, a model was established to describe the migration behavior and aggregation mechanism of $\mathrm{SiC}$ particles in silicon melt.

\section{Experimental procedure}

The experiment was carried out in a MTQZ-15-60 induction melting furnace, which is mainly composed of electric control system, induction system, cooling system, vacuum system and gas protection system, as shown in Fig. 1. A thermocouple (TC) was used to measure the temperature at the bottom of the graphite crucible. Silicon in the furnace was heated by the eddy current in a graphite crucible induced by high-frequency power under protective atmosphere conditions (Ar).

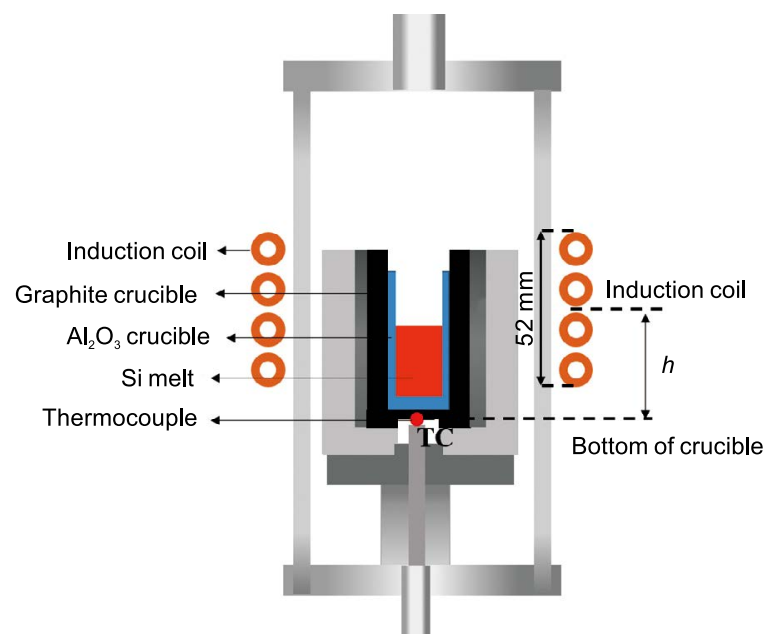

Fig. 1: Internal structure of induction furnace

Twenty-five gram high-purity $\mathrm{Si}$ and $25 \mathrm{~g}$ polysilicon scraps were used as raw materials for each experiment. The silicon scraps were placed at the bottom of the $\mathrm{Al}_{2} \mathrm{O}_{3}$ crucible. To observe the migration behavior and distribution of $\mathrm{SiC}$ in the silicon melt under different temperature fields, the TC temperature and the induction coil height, $h$ (distance from the center of coil to the bottom of crucible, as shown in Fig. 1) were changed. The detailed experimental parameters are shown in Table 1. During the directional solidification process, the pulling mechanism was drawn at a speed of $10.8 \mathrm{~mm} \cdot \mathrm{h}^{-1}$, and the vacuum degree in the furnace was maintained at $0.5 \mathrm{~atm}$.

The obtained silicon ingot of $\Phi 24 \mathrm{~mm} \times 40 \mathrm{~mm}$ was cut lengthwise down the middle. The detected area is the yellow section shown in Fig. 2. The methods used for microscopic analysis included electron probe X-ray microanalysis (EPMA),

Table 1: Experimental parameters

\begin{tabular}{ccc} 
Experiment & $\begin{array}{c}\text { Coil height } \\
\boldsymbol{h}(\mathbf{m m})\end{array}$ & $\begin{array}{c}\text { TC temperature } \\
(\mathrm{K})\end{array}$ \\
\hline 1 & 22.5 & 1,623 \\
2 & 42.5 & 1,623 \\
3 & 22.5 & 1,723
\end{tabular}

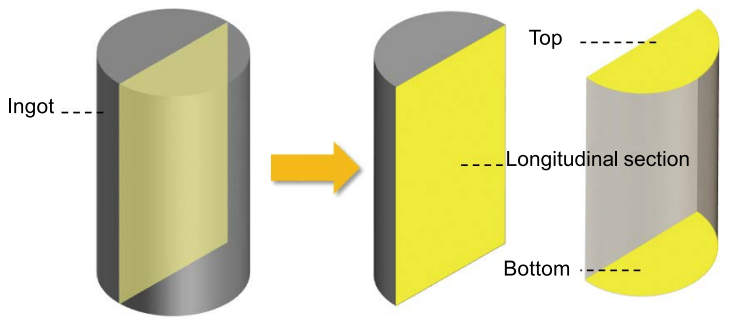

Fig. 2: Sampling position

scanning electron microscopy (SEM), and energy dispersive spectroscopy (EDS). Meanwhile, Image-Pro software was used to measure the particle size at different positions of the ingot.

Thermal and flow fields in the melt were numerically simulated by COMSOL Multiphysics 5.5 based on the experimental process parameters. In addition, the silicon melt was regarded as incompressible Newtonian viscous fluid, and the flow state was regraded as laminar flow in order to simplify the simulation process.

\section{Results and discussion}

\subsection{Macrostructure and microstructure}

Figure 3(a) shows the macroscopic morphology of the longitudinal section of the silicon ingot obtained by directional solidification at $1,623 \mathrm{~K}$, and the coil position $h=22.5 \mathrm{~mm}$. It can be seen that the particles are distributed mainly at the top and edges of the ingot, with a few particles deposited at the bottom. The particle enrichment regions were selected for SEM analysis. Figures 3(b) and (c) show the microstructure of particles at the top and bottom of the ingot, respectively. The particles at the bottom of the ingot are aggregated, while the particles at the top are relatively dispersed.

EPMA analysis on the particle enrichment region was further performed to observe the element distribution, as shown in Fig. 4. The particles with dark colors were identified as $\mathrm{SiC}$, while
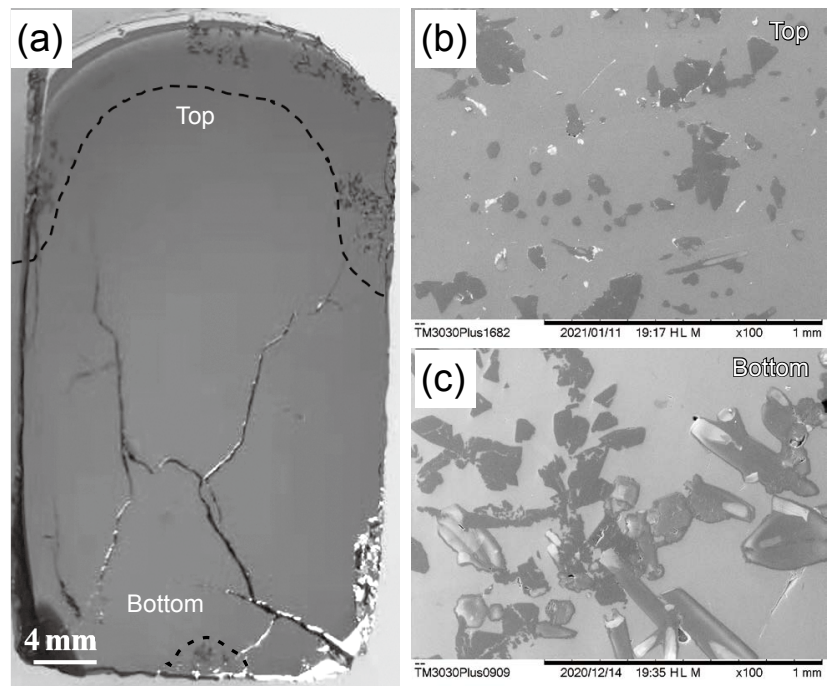

Fig. 3: Macromorphology (a) and micromorphology (b and c) of particles enrichment region along longitudinal section: (b) top of ingot; (c) bottom of ingot 

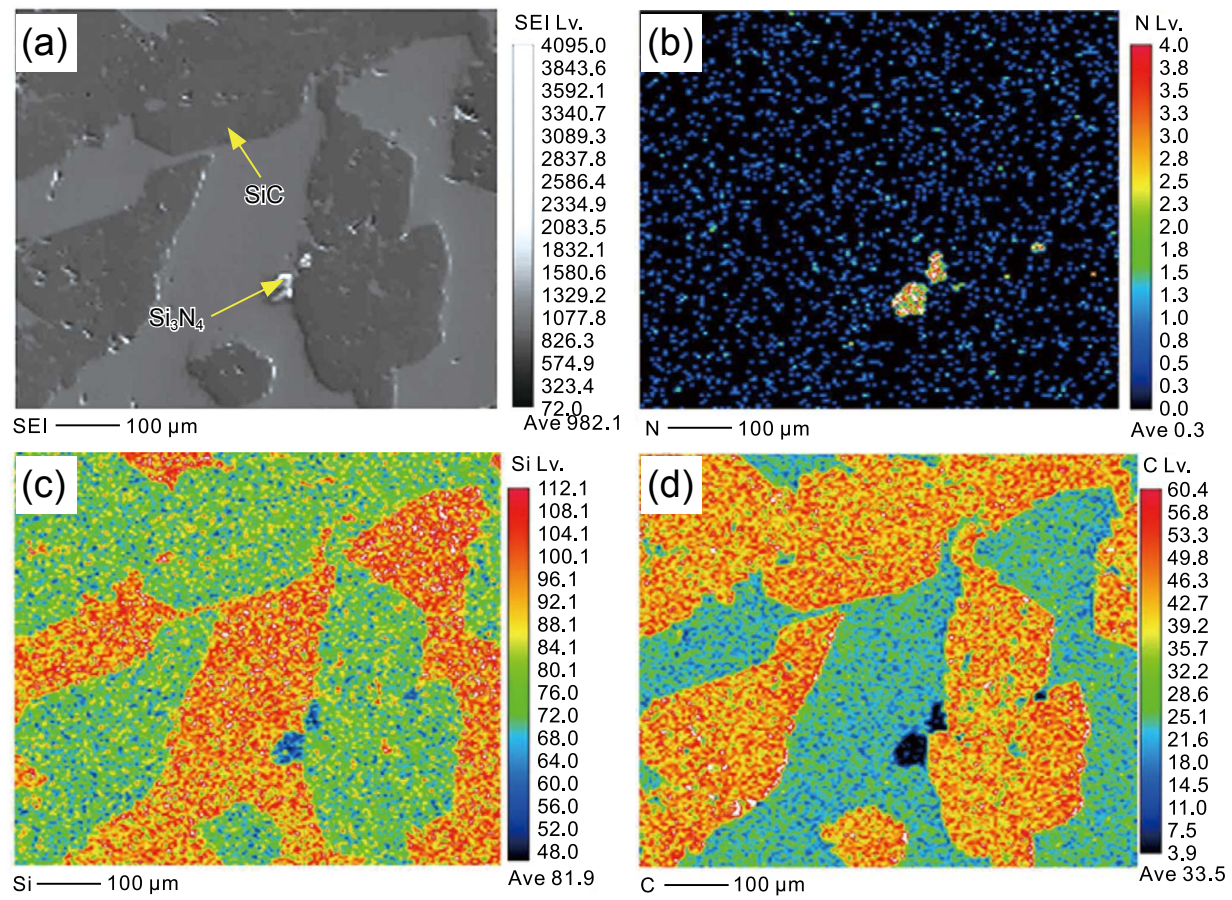

Fig. 4: EPMA mapping of elements distribution on particles enrichment region: (a) EPMA image; (b) N; (c) Si; (d) C

the bright-colored particles were detected as $\mathrm{Si}_{3} \mathrm{~N}_{4}$, which was derived from polysilicon scraps. According to previous study ${ }^{[23]}$, $\alpha$-SiC is unlikely to exist below $2,000 \mathrm{~K}$, so the $\mathrm{SiC}$ particles are $\beta$-SiC which is stable in the experiment.

\subsection{Migration behavior and aggregation mechanism of SiC particles}

The distribution of SiC particles is closely related to their precipitation, migration and aggregation behaviors. During the melting process, the $\mathrm{SiC}$ particles dissolve, which increases the concentration of $\mathrm{C}$ in the melt. During the directional solidification process, the $\mathrm{C}$ concentration in the melt is further increased due to its low segregation coefficient. If the $\mathrm{C}$ concentration in the melt exceeds its solid solubility, $\mathrm{SiC}$ will precipitate onto the hard particles or the crucible. Figure 5 shows a schematic diagram of the precipitation of $\mathrm{SiC}$ particles in the silicon melt from $1,685 \mathrm{~K}$ to $1,735 \mathrm{~K}^{[22]}$, where the solubility limit of carbon in the silicon melt $C_{\mathrm{L}}(T)$ can be expressed as a

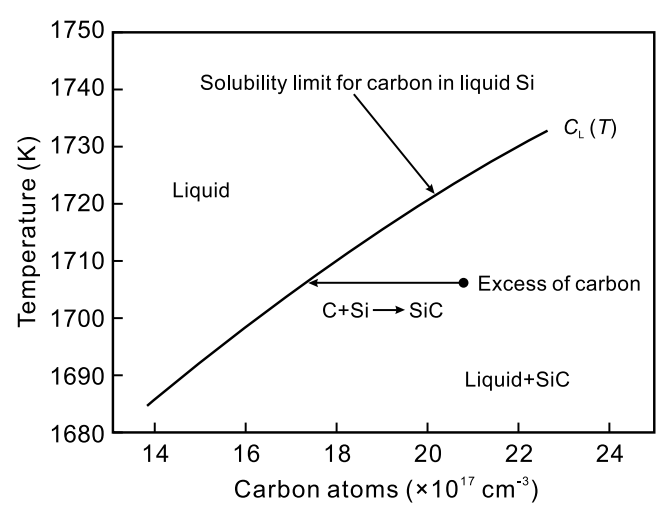

Fig. 5: Diagram of precipitation of SiC particles in silicon melt ${ }^{[22]}$ polynomial function approximately ${ }^{[22]}$ :

$$
C_{\mathrm{L}}(T)=8.625 \times 10^{-4} T^{2}-2.7643 T+2222.9
$$

where $T$ is the melt temperature, $\mathrm{K}$.

It can be calculated that when the melt temperature is $1,685 \mathrm{~K}-1,735 \mathrm{~K}$, the solid solubility of carbon in the silicon is between 11 and 19 ppmw.

To analyze the migration behavior of the $\mathrm{SiC}$ particles in the melt, numerical simulation on the temperature field and flow field of the silicon melt were carried out using COMSOL Multiphysics 5.5 software. Figure 6(a) shows the temperature field distribution of the melt at $1,623 \mathrm{~K}$ of TC temperature and $22.5 \mathrm{~mm}$ of coil height. It can be seen that the temperature at the center of the melt is higher than that at the bottom and top. Due to the inhomogeneous temperature distribution and the introduction of electromagnetic field, the flow of silicon melt is unstable, as shown in Fig. 6(b). The melt flows from the center of the crucible to the periphery, and the flow velocity $(v)$ at the

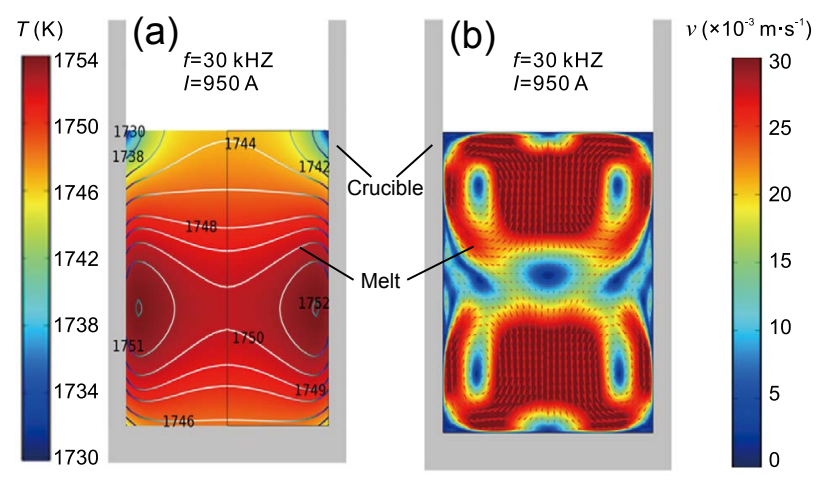

Fig. 6: Temperature field (a) and flow field (b) distribution of silicon melt 
center of the crucible is lower than the bottom and top, which leads to the appearance of vortex in the melt. These vortices cause the continuous movement of $\mathrm{SiC}$ particles in the melt and the enrichment of $\mathrm{SiC}$ particles in certain areas.

Figure 7 shows the distribution diagrams of $\mathrm{SiC}$ particles at $0 \mathrm{~min}$ and $15 \mathrm{~min}$ during melting process. It shows that $\mathrm{SiC}$ particles are uniformly distributed throughout the entire melt at the beginning of melting ( $0 \mathrm{~min}$ ). After melting for $15 \mathrm{~min}, \mathrm{SiC}$ particles are gradually enriched at the side, bottom and top of the crucible. The motion trajectory is consistent with the flow pattern of the melt. The $\mathrm{SiC}$ particles are forced to migrate to the side of the crucible due to the effect of electromagnetic force.

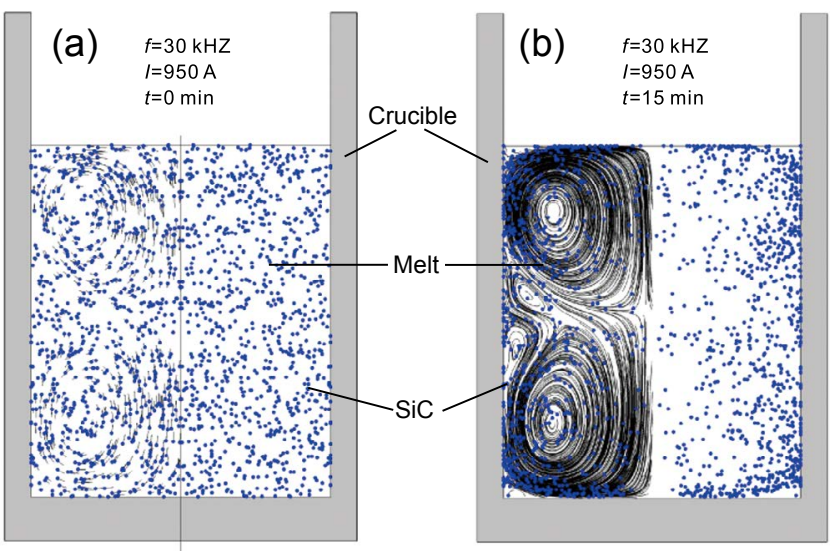

Fig. 7: Numerical simulated distribution of SiC particles at different melting times: (a) $0 \mathrm{~min}$; (b) $15 \mathrm{~min}$
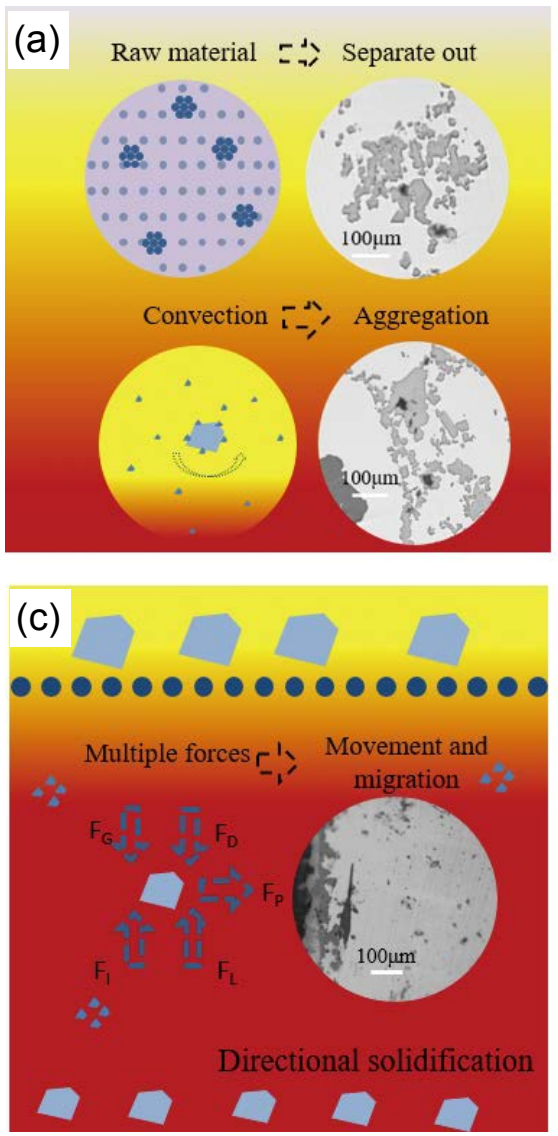

Compared with the morphology of the ingot shown in Fig. 3(a), it can be found that the simulation results on distribution of $\mathrm{SiC}$ particles are consistent with the experimental results.

During the melting process, $\mathrm{SiC}$ particles in the silicon scraps are separated out and entrained into the melt, meanwhile the particles aggregate with each other due to melt convection, as shown in Fig. 8(a). The large aggregation of $\mathrm{SiC}$ particles will sink and deposit at the bottom of the melt due to the effect of gravity, whereas the individual particles continue to move through the melt, as shown in Fig. 8(b).

Figure 8(c) shows that $\mathrm{SiC}$ particles are subjected to multiple forces under the action of the melt and solid-liquid interface, such as lift force $\left(F_{\mathrm{L}}\right)$, interface force $\left(F_{\mathrm{I}}\right)$, gravity $\left(F_{\mathrm{G}}\right)$, electromagnetic force $\left(F_{\mathrm{P}}\right)$ and drag force $\left(F_{\mathrm{D}}\right)$. Li et al. ${ }^{[24]}$ discussed the relationship between these forces and the migration behavior of $\mathrm{SiC}$ particles. They calculated the critical flow velocity $\left(v_{\mathrm{c}}\right)$ of the $\mathrm{SiC}$ particles as follows ${ }^{[24]}$.

$$
\begin{aligned}
v_{\mathrm{c}} & =\frac{\sqrt{6} d_{\text {min }}}{3 \mu R_{\mathrm{P}}}\left(\frac{d_{\text {min }}}{R_{\mathrm{P}}}\right)^{0.423}\left(\frac{k_{\mathrm{L}}}{k_{\mathrm{P}}}\right)^{2}\left[\Delta \gamma_{0}\left(\frac{a_{0}}{a_{0}+d_{\text {min }}}\right)^{2} \frac{k_{\mathrm{L}}}{k_{\mathrm{P}}}\right. \\
+ & \left.\frac{3.23}{\pi} \mu V_{\mathrm{rel}} R_{\mathrm{P}} \sqrt{\frac{\rho_{\mathrm{L}}}{\mu}\left(\frac{\mathrm{d} V_{\mathrm{L} X}}{d y}\right)_{\mathrm{avg}}}-\frac{2}{3} g R_{\mathrm{P}}^{2}\left(\rho_{\mathrm{P}}-\rho_{\mathrm{L}}\right)\right]
\end{aligned}
$$

where $g$ is the gravity acceleration, $R_{\mathrm{P}}$ is the radius of the particle, $\rho_{\mathrm{P}}$ and $\rho_{\mathrm{L}}$ are the density of the particle and melt, $k_{\mathrm{P}}$ and $k_{\mathrm{L}}$ are the thermal conductivity of the particle and melt, $\Delta \gamma_{0}$
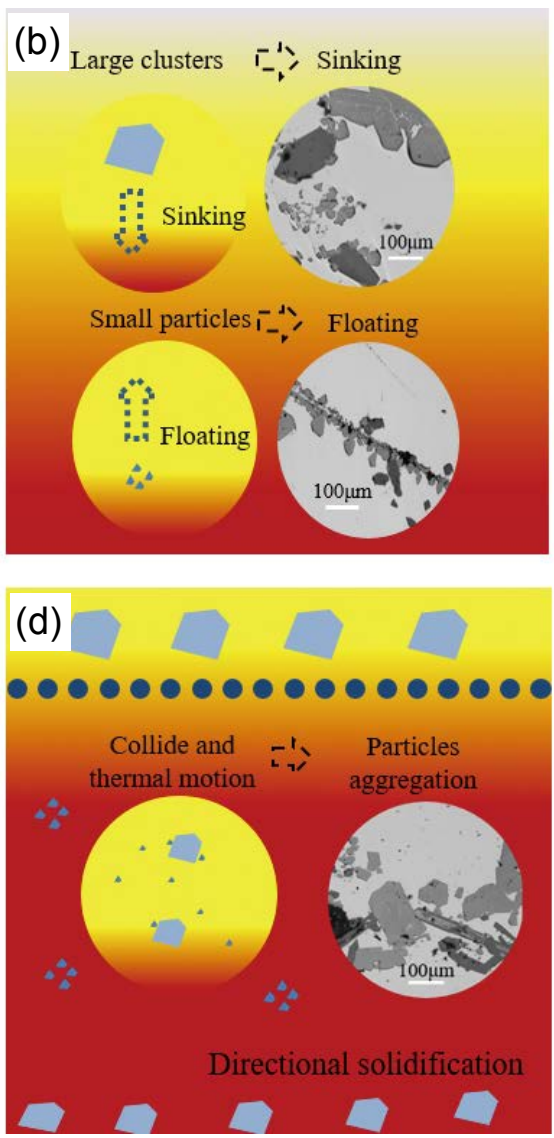

Fig. 8: Schematic diagram of migration behavior of SiC during directional solidification 
is the interfacial energy difference between the solid/particle and liquid/particle, $a_{0}$ is the diameter of an atom in the liquid metal, $d_{\min }$ is the gap width between particle and interface, $\mu$ is the dynamic viscosity of the liquid, $V_{\text {rel }}$ is the velocity of the particle relative to the liquid, $\left(\frac{\mathrm{d} V_{\mathrm{L} X}}{\mathrm{~d} y}\right)_{\mathrm{avg}}$ is the averaged velocity gradient within the momentum boundary layer.

The equation indicates that the migration rate of the particles decreases with the increase of particle size. At the beginning of solidification, the aggregation of $\mathrm{SiC}$ particles in the melt is easily engulfed by the solid-liquid interface, with the smallersized particles being pushed away. As the solid-liquid interface pushes forward, the $\mathrm{SiC}$ particles in the melt continues to collide and form aggregation, which are gradually engulfed by the solid-liquid interface during the directional solidification process. Meanwhile, the $\mathrm{SiC}$ particles are enriched at the edge of the melt due to the effect of electromagnetic force.

At the later stage of solidification, a great number of $\mathrm{SiC}$ particles are enriched at the top of the melt. The particles collide and aggregate with each other by irregular thermal motion in the residual silicon melt, as shown in Fig. 8(d). Once an aggregation occurs around a particle, the number density of particles in its neighborhood area will decrease, with the result that $\mathrm{SiC}$ particles in the melt migrate to the aggregation. In addition, the aggregation mechanism of $\mathrm{SiC}$ particles may involve Ostwald repening ${ }^{[25]}$. Carbon in the melt diffuses from smaller particles to larger particles due to the concentration gradient between SiC particles. Finally, a large aggregation of $\mathrm{SiC}$ particles is formed at the top of the ingot.

\subsection{Control of particles enrichment region}

Based on the migration behavior and aggregation mechanism mentioned above, the temperature field affects the flow state of the melt, and then changes the migration behavior of particles in the melt. Furthermore, the enrichment region of the particles can be controlled by adjusting the melting temperature and coil position. As shown in Fig. 9, the ingots were produced in different temperature fields. The particles are mainly enriched at the bottom when the temperature and coil position are $1,623 \mathrm{~K}$ and $42.5 \mathrm{~mm}$, respectively, as shown in Fig. 9(a-c). The enrichment regions of $\mathrm{SiC}$ particles will move up with the TC temperature increase and coil position decrease, as shown in Fig. 9(d-f). However, the micromorphology shows that the aggregation tendency of particles decreases with the increase of ingot height even at different temperature fields.
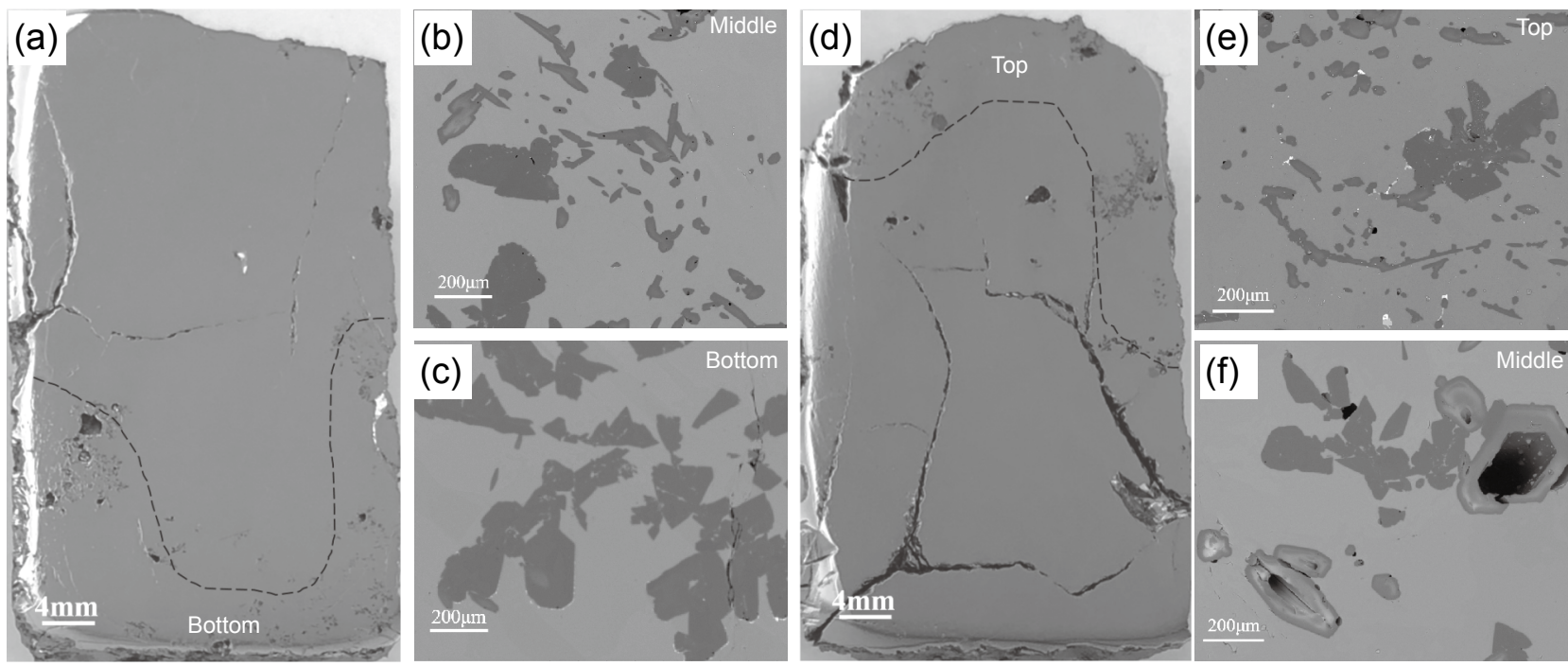

Fig. 9: Macromorphology and micromorphology of particles enrichment area at different experiment conditions: (a, b, c: $1,623 \mathrm{~K}, h=42.5 \mathrm{~mm}$; d, e, f: $1,723 \mathrm{~K}, h=22.5 \mathrm{~mm}$ )

All sizes of $\mathrm{SiC}$ particles (including individual particles and aggregated particles) are counted using Image-Pro software, and most of the SiC particles are between $20-400 \mu \mathrm{m}$ in size. The maximum and average sizes of $\mathrm{SiC}$ particles are measured and calculated, as shown in Table 2. It can be found that the maximum and average sizes of $\mathrm{SiC}$ particles decrease with the increase of ingot height, which means that the larger particles are more easily deposited at the bottom of the ingot during the directional solidification process.

Based on the experimental results (Fig. 3 and Fig. 9), the proportions of the enrichment regions of SiC particles at different ingot heights were calculated. As shown in Fig. 10, the distribution of the $\mathrm{SiC}$ particles is changed in different temperature fields. At 1,623 $\mathrm{K}$ and coil position of $22.5 \mathrm{~mm}$, a few particles deposite at the bottom of the ingot. However, the particles at the bottom disappear and enrich at the upper of the ingot as the TC temperature is increased. This phenomenon indicates that the increase of melt temperature promotes $\mathrm{SiC}$ particles to migrate to the top. However, it can be found that the enrichment region of $\mathrm{SiC}$ particles is mainly located at the bottom as the coil position moves up.

Figure 10 shows that the enrichment region of $\mathrm{SiC}$ particles in the silicon ingot varies significantly under different temperature fields. At 1,623 K, with a coil height of $22.5 \mathrm{~mm}$, the melt is completely in the action zone of electromagnetic field due to being in the coil. The aggregation of $\mathrm{SiC}$ particles 
Table 2: Size of SiC particles in ingot

\begin{tabular}{ccccc}
$\begin{array}{c}\text { TC temperture } \\
(\mathrm{K})\end{array}$ & $\begin{array}{c}\text { Coil height } \\
(\mathrm{mm})\end{array}$ & Area & $\begin{array}{c}\text { Maximum diameter } \\
(\boldsymbol{\mu m})\end{array}$ & $\begin{array}{c}\text { Average diameter } \\
(\boldsymbol{\mu m})\end{array}$ \\
\hline 1,623 & 22.5 & Bottom & 657.9 & 126.8 \\
1,623 & 22.5 & Top & 191.8 & 55.7 \\
1,623 & 42.5 & Bottom & 471.51 & 143.4 \\
1,623 & 42.5 & Middle & 260.5 & 73.1 \\
1,723 & 22.5 & Middle & 367.0 & 99.8 \\
1,723 & 22.5 & Top & 316.7 & 68.0
\end{tabular}

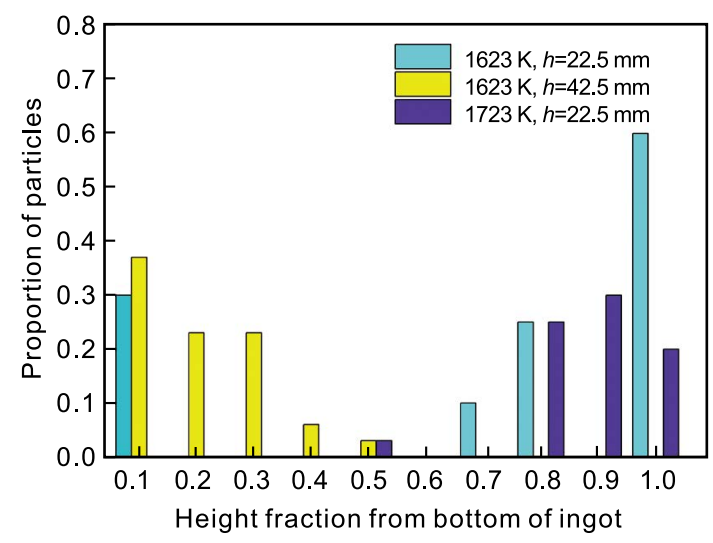

Fig. 10: Cumulative area distribution of $\mathrm{SiC}$ inclusions at different heights of ingot

in the melt are deposited on the bottom, while individual $\mathrm{SiC}$ particles migrate to the top of the ingot. As the coil height moves up ( $h=42.5 \mathrm{~mm}$ ), the turbulence of the upper melt is more intense due to the higher intensity of the electromagnetic field. The turbulence causes individual $\mathrm{SiC}$ particles to collide with each other, forming the aggregation of $\mathrm{SiC}$ particles. However, with the particles moving down, the lift force on the $\mathrm{SiC}$ particles decreases. While, the action of gravity makes the SiC particles sink and deposit at the bottom of the melt.

When the temperature is increased to $1,723 \mathrm{~K}$, the flow velocity of the melt is accelerated. The $\mathrm{SiC}$ particles are uniformly distributed and continuously move in the melt. During the solidification process, it is difficult for the $\mathrm{SiC}$ particles to form aggregation. They will be repelled to the top of the melt by the solid-liquid interface. Finally, the $\mathrm{SiC}$ particles form an enrichment region at the top of the ingot. This means that the $\mathrm{SiC}$ particles can be effectively separated from silicon scraps.

\section{Conclusions}

The migration behavior and aggregation mechanism of $\mathrm{SiC}$ particles were discussed systematically, and the following conclusions are obtained:

(1) The $\mathrm{SiC}$ particles move continuously and collide with each other due to the effect of melt convection. The particles tend to form aggregation by collision and Ostwald repening mechanism.
(2) Larger aggregation of $\mathrm{SiC}$ particles is easily entrapped by the solid-liquid interface, while the smaller $\mathrm{SiC}$ particles are repelled to the top of melt. Some particles are captured near the crucible inside wall under the action of electromagnetic force.

(3) With the increase of the melt temperature, the enrichment region of $\mathrm{SiC}$ particles moves upward due to the accelerated melt flow. In addition, the particles can be deposited at the bottom by adjusting the electromagnetic field.

This work proves that the enrichment region of $\mathrm{SiC}$ particles can be controlled by adjusting the temperature field distribution of the melt. The particles can be effectively separated from the silicon scraps by alternating electromagnetic fields and directional solidification.

\section{Acknowledgements}

This study was financially supported by the Specialized Research Fund for the National Natural Science Foundation of China (51974057), the Open Project of State Key Laboratory of Advanced Special Steel, Shanghai Key Laboratory of Advanced Ferrometallurgy, Shanghai University (SKLASS 2019-19), and the Science and Technology Commission of Shanghai Municipality (No. 19DZ2270200), and the Innovation Team Project for Key Fields of Dalian (Grant No. 2019RT13).

\section{References}

[1] Luo T, Lü G, Ma W, et al. Numerical and experimental study of vacuum directional solidification purification process for SoG-Si in metallurgical route. J. Cryst. Growth, 2013, 384: 122-128.

[2] Njuguna B K, Li J, Tan Y, et al. Grain refinement of primary silicon in hypereutectic Al-Si alloys by different P-containing compounds. China Foundry, 2021, 18: 37-44.

[3] Lotnyk A, Bauer J, Breitenstein O, et al. A TEM study of SiC particles and filaments precipitated in multicrystalline $\mathrm{Si}$ for solar cells. Sol. Energ. Mat. Sol. C., 2008, 92(10): 1236-1240.

[4] Yu Q, Liu L, Zhong G, et al. Control of impurities transport in an industrial directional solidification furnace for silicon ingots basing on computer modeling. J. Cryst. Growth, 2013, 1547: 652-658.

[5] Du G, Chen N, Rossetto P. On-wafer investigation of SiC and $\mathrm{Si}_{3} \mathrm{~N}_{4}$ inclusions in multicrystalline $\mathrm{Si}$ grown by directional solidification. Sol. Energ. Mat. Sol. C., 2008, 92(9): 10591066. 
[6] Du G, Zhou L, Rossetto P, et al. Hard inclusions and their detrimental effects on the wire sawing process of multicrystalline silicon. Sol. Energ. Mat. Sol., 2007, 91(18): 1743-1748.

[7] Bauer J, Breitenstein O, Rakotoniaina J. Electronic activity of $\mathrm{SiC}$ precipitates in multicrystalline solar silicon. Phys. Status. Solidi (a), 2007, 204: 2190-2195.

[8] Ceccaroli B, Lohne O, Øvrelid E J. New advances in polysilicon processes correlating feedstock properties and good crystal and wafer performances. Phys. Status. Solidi C, 2012, 9: 2062-2070.

[9] Breitenstein O, Rakotoniaina J P, Werner M, et al. Shunt types in crystalline silicon solar cells. Prog. Photovolt.: Res. \& Appl., 2004, 12: 529-538.

[10] Wu Y F, Chen Y M. Separation of silicon and silicon carbide using an electrical field. Sep. Purif. Technol., 2009, 68: 70-74.

[11] Liu Y, Kong J, Zhuang $Y$, et al. Recycling high purity silicon from solar grade silicon cutting slurry waste by carbothermic reduction in the electric arc furnace. J. Clean Prod., 2019, 224: 709-718.

[12] Ciftja A, Zhang L, Engh T A, et al. Purification of solar cell silicon materials through filtration. Rare Metals, 2006, 25: 180-185.

[13] Xue H, Lv G, Ma W, et al. Separation mechanism of primary silicon from hypereutectic Al-Si melts under alternating electromagnetic fields. Metall. Mater. Trans. A, 2015, 46: 2922-2932.

[14] Tsai T H, Shih Y P, Wu Y F. Recycling silicon wire-saw slurries: Separation of silicon and silicon carbide in a ramp settling tank under an applied electrical field. J. Air Waste Manag. Assoc., 2013, 63: 521-527.

[15] Zhang L, Ciftja A. Recycling of solar cell silicon scraps through filtration, Part I: Experimental investigation. Sol. Energ. Mat. Sol. C., 2008, 92(11): 1450-1461.

[16] Bao L, Zhao D, Zhao Y, et al. Effect of harmonic magnetic field and pulse magnetic field on microstructure of high purity $\mathrm{Cu}$ during electromagnetic direct chill casting. China Foundry, 2021, 18(2): $141-146$.
[17] Xue H, Lv G, Ma W, et al. Experimental study on the segregation of primary silicon from the hypereutectic Al-Si melts in the electromagnetic directional solidification. Trans. Tech. Publications C, 2015, 809: 363-368.

[18] Wei K, Yang S, Wan X, et al. Review of silicon recovery and purification from saw silicon powder. JOM, 2020, 72: 26332647.

[19] Trempa M, Reimann C, Friedrich J, et al. The influence of growth rate on the formation and avoidance of $\mathrm{C}$ and $\mathrm{N}$ related precipitates during directional solidification of multi crystalline silicon. J. Cryst. Growth, 2010, 312: 1517-1524.

[20] Muhlbauer A, Diers V, Walther A, et al. Removal of C/SiC from liquid silicon by directional solidification. J. Cryst. Growth, 1991, 108(1-2): 41-52.

[21] Teng Y, Chen J, Lu W, et al. The carbon distribution in multicrystalline silicon ingots grown using the directional solidification process. J. Cryst. Growth, 2010, 312: 1282-1290.

[22] Liu L, Nakano S, Kakimoto K. Carbon concentration and particle precipitation during directional solidification of multicrystalline silicon for solar cells. J. Cryst. Growth, 2008, 310: 2192-2197.

[23] Søiland $\mathrm{A}, \varnothing$ vrelid $\mathrm{E}$, Engh $\mathrm{T}$, et al. $\mathrm{SiC}$ and $\mathrm{Si}_{3} \mathrm{~N}_{4}$ inclusions in multicrystalline silicon ingots. Mater. Sci. Semicond. Process., 2004, 7(1-2): 39-43.

[24] Li P, Lin M, Tong S, et al. Recycling of silicon scraps by directional solidification coupled with alternating electromagnetic field and its electrical property. Sol. Energ. Mat. Sol. C., 2020, 211: 110540.

[25] Dubrovskii V G, Kazansky M A, Nazarenko M V, et al. Numerical analysis of Ostwald ripening in two-dimensional systems. J. Chem. Phys., 2011, 134: 094507. 